\title{
EDUCAÇÃO PATRIMONIAL E ENSINO DE HISTÓRIA: POTENCIAIS DO USO DE DOCUMENTAÇÃO ARQUIVÍSTICA
}

\author{
EDUCATION SHEET AND TEACHING OF HISTORY: POTENTIAL OF USE OF \\ DOCUMENTATION ARCHIVAL
}

Elisgardenia Oliveira Chaves ${ }^{1}$

\begin{abstract}
RESUMO: Os documentos escritos como objeto de estudos e fonte histórica podem e devem ser utilizados como recursos didáticos em todos os níveis na educação histórica. Assim, a partir das relações da produção do conhecimento histórico com o conhecimento histórico escolar, este texto objetiva discutir possibilidades teórico-metodológicas sobre a utilização de documentação arquivística, com ênfase nos registros eclesiásticos de casamentos, batismos e óbitos, para o desenvolvimento da educação patrimonial e como instrumentos didáticos nas práticas de ensino de história.
\end{abstract}

Palavras-chave: Ensino de História. Educação Patrimonial. Arquivos Eclesiásticos.

ABSTRACT: Written documents as the object of study and historical source can and should be used as teaching resources at all levels in history education. Thus, from the relations of production of historical knowledge with school historical knowledge this text discusses theoretical and methodological possibilities for the use of archival documentation, with emphasis on church records of marriages, baptisms and deaths, for the development of heritage education and how didactic practices in the teaching of history.

Keywords: History Teaching. Heritage Education. Ecclesiastical Archives.

\footnotetext{
1 Universidade Federal de Minas Gerais. Doutora em História Social da Cultura pela Universidade Federal de Minas Gerais - UFMG
} 


\section{Introdução}

A opção por trabalhar, nesse texto, o patrimônio arquivístico como possibilidade para a educação patrimonial no ensino de história não é aleatória. Além das potencialidades, mais adiante discutidas, de antemão nos chama a atenção a raridade de produções acadêmicas sobre ensino de história que têm nos arquivos documentais escritos suportes de pesquisas histórico-didáticas. ${ }^{2}$

No Brasil, as pesquisas historiográficas que têm documentação arquivística e escrita como fonte de estudo, desde as últimas décadas do século $X X$, vêm alargando-se e consolidando-se. Precisam, portanto, ganhar espaço de interesses no ensino, proporcionar estudos de casos sedimentados por relatos de experiências, discussões teóricas e metodológicas, definição de documento e problematização sobre o conceito de história. Para Hermeto e Pereira (2012, p. 399), "a análise de um 'caso' é um tipo de prática científica que é mais do que um exemplo. É uma forma de pensamento e uma forma de argumentação sobre a singularidade, a fim de verificar a implicação recíproca entre a articulação de uma teoria e o desenvolvimento de uma pesquisa".

A proposta, a seguir, embora não se trate, ainda, de um estudo de caso, pretende contribuir para o debate e, sobretudo, para a formação continuada de docentes de todos os segmentos e auxiliar o professor de ensino básico de história a desenvolver práticas pedagógicas de educação patrimonial, tomando os documentos escritos/eclesiásticos como objeto/fonte e recursos didáticos para o conhecimento histórico.

\footnotetext{
${ }^{2}$ As constatações pautam-se nas análises sobre os anais de eventos voltados para o ensino de história, como os Simpósios Temáticos do XXVI Simpósio Nacional de História ANPUH 50 anos, realizado em julho de 2011, na cidade São Paulo, bem como, dos eventos próprios da área, especificamente o IX Encontro Nacional de Pesquisadores em Ensino de História (ENPEH), realizado em Florianópolis, no ano de 2011, e o VIII Encontro Nacional Perspectivas do Ensino de História, acontecido em Campinas, São Paulo, em julho de 2012. Temos consciência de que os trabalhos apresentados e discutidos nesses eventos não representam o todo do que se pesquisa sobre ensino de história no Brasil. No entanto, em grande medida, os anais desses eventos condensam resultados de pesquisas acadêmicas concluídas ou em andamento realizadas em programas de Pós-Graduação em história e, sobretudo em educação. No geral, as preocupações giram em torno da descrição arquivística, digitalização e acesso à documentação de arquivos públicos para ações educativas: para que, como se digitaliza, o que se digitaliza, para quem, que memória preservar. Em síntese, não falam de um suporte em específico, de documentação escrita, de metodologias para o ensino, mas de possibilidades, expectativas e procedimentos de preservação.
} 


\section{Patrimônio, memória e história: o uso do documento na produção/ensino do conhecimento histórico.}

De acordo com Oriá (1998), patrimônio cultural pode ser dividido em três grandes categorias. Primeiramente os elementos pertencentes à natureza, ao meio ambiente - rios, peixes, vales, montanhas - que circundam os rios, recursos naturais, habitat natural. Em segundo lugar, os bens culturais conhecimento, técnicas, saber e o saber fazer - compreendendo toda capacidade de sobrevivência do homem em seu meio ambiente. Essa categoria inclui os elementos tangíveis do patrimônio cultural. E, por fim, os bens culturais propriamente ditos que englobam toda sorte de coisas, objetos, artefatos, obras e construções obtidas a partir do próprio meio ambiente e do saber-fazer humano. O tripé forma a dimensão natural ou ecológica, a dimensão histórica, artística e a documental.

Essas categorias, segundo Caimi e Cassol (2012), comportam o patrimônio material, composto por um conjunto de bens classificados de acordo com sua natureza - arqueológico, paisagístico e etnográfico; histórico; belas artes; artes aplicadas; e o patrimônio imaterial: manifestações musicais, artísticas e religiosas populares.

A par dessa definição, o que não seria patrimônio? Tendemos a concordar com François Hartog (2006), quando ao discutir a redefinição da "memória" e do "patrimônio" dentro do novo "regime de historicidade" que o Ocidente vive após a Queda do Muro de Berlim, que ocorreu em 1989, chama a atenção para o processo de presentismo - indícios, sintomas de nossa relação com o tempo -, ao qual o regime de historicidade vem passando. Em consequência verifica-se:

\footnotetext{
A patrimonialização galopante dos anos 1990 em que 'no decorrer destes anos, a vaga patrimonial, em sintonia com a da memória, portanto, tomou cada vez mais amplitude até tender para este limite que seria o 'tudo patrimônio'. Assim como se anuncia ou se reclama memórias de tudo, assim tudo seria patrimônio ou suscetível de tornar-se. A mesma inflação parece reinar. A patrimonialização ou a musealização se aproximando sempre mais do presente, foi preciso estipular, por exemplo, 'que nenhuma obra de arquiteto vivo seria legalmente considerada como monumento histórico'. Isto é um indício muito claro deste presente que se historiciza, já evocado (HARTOG, 2006, p. 268).
} 
Nesse sentido, para o autor, "os lugares da Memória de Pierre Nora chegaram ao diagnóstico de uma patrimonialização [...] a mudança de um regime de memória a outro nos fazia sair da 'história-memória' para entrar em uma 'história-patrimônio"'. (HARTOG, 2006, p. 266)

Isso, porque, Pierre Nora (1993, p. 8), no texto Entre memória e História: a problematica dos lugares, afirma que "há locais de memória porque não há mais meios de memória." Os "meios de memórias foram destruídos pelo fenômeno da mundialização, globalização, colonização, industrialização, que ocasionaram o fim das sociedades-memória, mantenedoras e transmissoras dos valores" (p. 9). Esse momento marcado por um produtivismo arquivístico, o que "nós chamamos de memória é a constituição gigantesca e vertiginosa do estoque material daquilo que nos é impossível lembrar" (p. 15).

Para Nora (1993, p. 9), "à medida que desaparece a memória tradicional, nós nos sentimos obrigados a acumular religiosamente vestígios, sinais visíveis do que foi, como se esse dossiê cada vez mais prolífero devesse se tornar prova em não se sabe que tribunal da história" E "desde que haja rastro, distância, mediação, não estamos mais dentro da verdadeira memória, mas dentro da história" (p. 15). Portanto, memória não é sinônimo de história:

\begin{abstract}
A memória é a vida, sempre carregada por grupos vivos e, nesse sentido, ela está em permanente evolução, aberta a dialética da lembrança e do esquecimento, inconsciente de suas deformações sucessíveis, vulnerável a todos os usos e manipulações [...] A história e a reconstrução sempre problemática e incompleta do que não existe mais. A memória é um fenômeno sempre atual, um elo vivo no eterno presente; a história é uma representação do passado. (NORA, 1993, p. 9)
\end{abstract}

A equação para compreendermos as relações e distinções entre memória, patrimônio e história é complexa. Ao se fazer história, basicamente se historiciza patrimônio, haja vista serem as memórias que constituem o patrimônio material e imaterial - e que compõem os lugares da memória, os monumentos, os documentos/fontes para produção histórica. Portanto, ao se produzir/ensinar história, necessariamente estuda-se patrimônio. Por esse prisma, patrimônio não é história, é documento. 
Por educação patrimonial "entende-se a utilização de museus, monumentos históricos, arquivos, bibliotecas - os lugares e suportes de memória - no processo educativo, a fim de desenvolver a sensibilidade e a consciência dos educadores e futuros cidadãos da importância da preservação desses bens culturais" (ORIÁ, 1998 p. 133). Educar para conhecer. Conhecer para preservar. Preservar os bens culturais para que se possa conhecer/produzir conhecimento sobre uma sociedade em determinado tempo e espaço, isto é história. Essa deve ser a finalidade da educação patrimonial. Partindo desse ponto, as "memórias de tudo", o "produtivismo arquivistico," têm muito a contribuir para a história.

As considerações de Marc Bloch (2001) e Jaques Le Goff (2003) são emblemáticas para aprofundarmos a discussão. De acordo com o primeiro autor, o homem e o tempo são os objetos de estudo da ciência histórica. Esse homem, enquanto sujeito e objeto do conhecimento histórico, passeia por diferentes temporalidades: o tempo sobre o qual ele escreve a história (passado) e o tempo em que a história é escrita (presente). Se tudo que vem do homem e serve ao homem é passível que se transforme em material para o conhecimento, esse homem - historiador - através de conceitos e métodos apropria-se do legado humano para a produção/ensino do conhecimento histórico. Essa produção humana, portanto, configura-se em documentos (BLOCH, 2001).

Documento, por sua vez, na definição de Le Goff, é monumento. Sua produção está condicionada a vários fatores, informa sobre o modo de vida de quem os produziu, sua inserção social e, voluntaria ou involuntariamente, ao impor ao futuro a sociedade imagem de si próprio, pereniza, monumentaliza situações, ideias, ações. No entanto, para que a produção humana se transforme em documento para a história, é necessário desmontar, desestruturar essa construção e analisar as condições de produção do documento-monumento (LE GOFF, 2003). E, isso, se faz com problematizações ao documento, para que se chegue às temporalidades, aos sujeitos e às relações existentes e, a partir daí, se transforme os documentos em fontes capazes de informar sobre as relações dos homens no tempo.

A meu ver, sendo o patrimônio material e imaterial, os documentos/fontes para produção histórica os instrumentos didáticos, teórico-metodológicos 
utilizados para a educação patrimonial deverão ser os mesmos utilizados pelos profissionais de história no bojo de sua atuação profissional.

No Brasil, a "patrimonialização galopante" manifesta-se mais intensamente a partir da década de 1980, numa conjuntura marcada pelo processo de redemocratização, movimentos sociais e revisões historiográficas. Até esse momento, segundo Ricardo Oriá (1998, p. 131), "patrimônio era associado às palavras monumentos e edifícios antigos." Isso se deve à política de preservação desenvolvida pelo Serviço do Patrimônio Histórico Artístico Nacional (SPHAN), criado em 1937. Por essa política, preservaram-se "as igrejas barrocas, os fortes militares, as casas-grandes e os sobrados coloniais. Esqueceram-se as senzalas, os quilombos, as vilas operárias e os cortiços" (p. 131). Pretendia-se excluir "as diferenças e a pluralidade étnico-cultural de nossa formação histórica. A memória que se queria preservar: memória unívoca e de um passado homogêneo e de uma História sem conflitos e contradições sociais" (p. 132).

A redimensão do conceito de patrimônio teve impulso com o Decreto $\mathrm{n}^{0}$ 3.551 de agosto de 2000, que é um novo instrumento de preservação aos bens culturais de ordem imaterial ou intangível. O decreto "institui o Registro de Bens Culturais de Natureza Imaterial que constituem patrimônio cultural brasileiro, cria o Programa do Patrimônio Imaterial e dá outras providências" (BRASIL, 2000, p. 1).

Entendeu-se que havia urgência em se criar um mecanismo de tombamento e preservação "viável que tutelasse os bens imateriais, muito mais susceptíveis ao desaparecimento, frente à onda avassaladora da homogeneização cultural decorrente do processo de globalização" (FERNANDES, 2011, p. 6).

Daí, as manifestações musicais, artísticas e religiosas populares, finalmente, poderiam receber o reconhecimento como patrimônio cultural da nação, pelo Instituto do Patrimônio Histórico e Artístico Nacional (IPHAN), órgão que atua na gestão, proteção e preservação do patrimônio histórico e artístico no Brasil.

Um atributo constitucional relativo à questão do patrimônio é o reconhecimento por parte do Estado da necessidade de se preservar a documentação pública. $\mathrm{O}$ art. 216, § 20 da Constituição Federal de 1988 estabelece "cabem à administração pública, na forma da lei, a gestão da documentação governamental e as providências para franquear sua consulta a 
quantos dela necessitem" (BRASIL, 1988). Desse modo, constata-se que os documentos são também parte integrante do Patrimônio Cultural Brasileiro, necessitando, portanto, de proteção jurídica.

Ademais, tem-se a Lei no. 8.159, de 8 de janeiro de 1991, que "dispõe sobre a política nacional de arquivos públicos e privados e dá outras providências" (BRASIL, 1991).

Assim, "ao lado das bibliotecas e museus, os arquivos são importantes suportes da memória, sem os quais fica quase impossível o acesso às fontes de nosso passado, uma vez que sem documentos não há história possível" (FERNANDES, 2011, p. 6).

Atrelada as políticas de preservação patrimonial, não se pode esquecer:

A emergência dos movimentos sociais populares, protagonizados pela mobilização dos trabalhadores, mulheres, negros, índios, homossexuais, etc., reivindicam para si o alcance e o exercício dos direitos de cidadania e a participação política no processo decisório nacional (ORIÁ, 1998, p. 129).

Esses movimento colocam na ordem do dia o interesse pelo "resgate" de sua memória, como instrumento de luta e afirmação de sua identidade étnica e cultural (ORIÁ, 1998).

No Brasil, as décadas de 1980 e 1990 propiciaram uma conjuntura favorável às transformações:

Não se pode deixar de salientar o fato de que a construção da democracia no Brasil a partir dos anos 1980 impôs a necessidade de uma revisão historiográfica capaz de valorizar a diversidade da sociedade nacional. A democracia estabelece o Estado não mais como a única medida da sociedade. Certamente os movimentos de base local e em torno de causas particulares conjugados com a organização de eleições em nível regional, estadual e nacional promove uma discussão que coloca a questão da participação da sociedade em diferentes perspectivas. Isso desafia a compreensão da História e destaca a importância e a necessidade de uma historiografia tão diversificada quanto à sociedade, capaz de reconhecer e analisar os vários espaços e atores sociais. Uma das faces evidentes desse processo de atualização historiográfica com a sociedade, nesse contexto de reordenamento das estruturas sociais é a multiplicação no país, em toda parte de museus estaduais, municipais e comunitários de diversos tipos. A democracia impõe a compreensão do passado para a definição de laços sociais que a dinamizam no presente (KNAUSS, 2011, p. 19). 
Nesse período de redemocratização marcado também por reformas curriculares, pesquisadores do ensino, como Le Goff, Suzane Citron, Tompson, Walter Benjamim, Foucault, Marcos Silva, Conceição Cabrine, Helenice Ciampi e, sobretudo, Déa Fenelon e Elza Nadai, buscou-se "na História Nova, referencial teórico e temático que orientavam suas produções" (ZAMBONI, 2000/2001, p. 108- 109).

No processo geral de redefinições de políticas públicas da década de 90, criou-se a Lei de Diretrizes e Bases da Educação - Lei n 9.394/96 - sedimentada por concepções da História Nova, com abertura para novas temáticas (cotidiano, homem comum, história local, lugares de memória, história da América), compreensões de tempo e método, tem ampliado o campo de pesquisa/ensino em História (BRASIL, 1996).

A LDB enfatiza, no seu artigo 26, que "a parte diversificada dos currículos dos ensinos fundamental e médio deve observar as características regionais e locais da sociedade e da cultura, o que abre espaço para a construção de uma proposta de ensino voltada para a divulgação do acervo cultural dos estados e municípios" (ORIÁ, 1998, p. 142).

Em consonância com a LDB, os Parâmetros Curriculares Nacionais (PCN) para o ensino fundamental, elaborados pelo Ministério da Educação (MEC), ao introduzir na educação básica os chamados temas transversais, sobretudo os temas que tratam do meio ambiente e da pluralidade cultural, possibilitam à escola o estudo do patrimônio histórico e a consequente adoção de projetos de educação patrimonial. No entanto, Régis Lopes Ramos afirma que ao tratar a memória (ou o patrimônio) o grande desafio para os Parâmetros Curriculares Nacionais ( $\mathrm{PCN}$ ) de história é a diferença entre história e memória:

É nítida a ideia de criticar os monumentos dos "grupos sociais dominantes" e isso se trata, evidentemente, de um procedimento da própria pesquisa histórica. Por outro lado, o verbo criticar parece se reduzir ao verbo ampliar. Assim como ocorre em outros documentos oficiais, sobretudo quando há referências ao "direito à memória", essa linha de raciocínio permite a seguinte conclusão, geralmente abraçada pelas "ONGs": diante do patrimônio da elite excludente, a solução seria resgatar o patrimônio do povo excluído. Há certa insegurança de se colocar a memória como objeto da história (RAMOS, 2010, p. 406). 
Ainda para Ramos (2010, p. 407), "a produção de memórias e identidades faz parte da defesa da pluralidade cultural. Sobre isso, os PCN trouxeram um avanço significativo, não somente para o ensino de História, mas para a própria prática educativa em sentido mais amplo." Na realidade "a produção de memórias e identidades múltiplas não é tarefa do ensino de História" (p. 407), pois, "o que o saber histórico almeja é perceber a historicidade dessas produções, localizando-a em conflitos de experiências e expectativas socialmente constituídas" (p. 407). E exemplifica seu argumento:

Cito um exemplo: a crítica à participação da igreja católica no
processo colonizador não deveria desembocar necessariamente na
valorização das religiões africanas, indígenas ou protestantes. Ao
pensamento histórico não caberia valorizações (ou intolerâncias)
espeć́ficas no campo das crenças. [...] O interesse crítico da
história seria perceber como as várias religiões são experiências de
pessoas que vivem em espaços e tempos específicos, dentro de
certas redes de tensões e negociações que envolvem variados
interesses. [...] Desse modo, não se pode defender que o combate
à história católica vem por uma história protestante, espírita ou
afrodescendente, assim como a reflexão sobre as memórias
nacionalistas (fabricantes de homogeneidade) não se resolve com
o incentivo às memórias das minorias (fabricantes de
heterogeneidade). A saída para o ensino de História atento ao
respeito pela diversidade cultural não é transformar-se em ensino
de memória. A memória faz parte das lutas políticas. Cabe ao
ensino de História fornecer instrumentos para se perceber como
isso acontece no tempo e no espaço (RAMOS, 2010, p. 408).

Em outras palavras, se a "patrimonialização galopante" quer tudo preservar, ampliar, destacar e manter presente memórias, como selecionar essas "memórias relegadas", esquecidas e/ou em processo de esquecimento? Como descartar as memórias ditas "dominantes"? Patrimônio para quem? Para o profissional de história não faz sentido perspectivas que verticalizam a discussão pelo prisma dos vencedores e dos vencidos. Mais uma vez, evidencia-se a máxima de que memória não é história. É somente por meio do processo de desmonumentalização dessas memórias/documentos que se pode juntar e encontrar possibilidades de sentidos para dar respostas aos questionamentos que movem a construção da pesquisa/ensino. 


\section{Uso do patrimônio arquivístico na produção do saber histórico escolar: leitura documental e construções de capacidades cognitivas.}

Diante da infinidade de bens culturais possíveis de promover a educação patrimonial, a partir de um suporte de memória no ensino de história, a ênfase, aqui, se fará sobre o patrimônio documental arquivístico e escrito que, por sua vez, insere-se no rol das diferentes materiais didáticos para o ensino de história. Os documentos, enquanto materiais didáticos, segundo Circe Bittencourt (2008), ao contrário dos suportes informativos como livros didáticos, atlas, dicionários, CDs, DVDs e materiais de computador, foram produzidos sem intenções pedagógicas e, somente por intermédio do professor, se transformam em recursos didáticos. Para a autora, os materiais didáticos dividem-se em três tipos: escritos, materiais (objetos de arte ou do cotidiano, construções) e visuais (imagens gráficas, musicais).

Para Miriam Hermeto, por esses materiais didáticos (linguagens e/ou documentos) possibilitar construir capacidades de leitura de mundo dos estudantes - sujeitos, cidadãos, trabalhadores - podem ser tomados como instrumento didático privilegiado no ensino de história. Assim, como a autora, acreditamos que ensinar História é ensinar teoria e metodologia. (HERMETO, 2012) No entanto, a grande questão reside nos desafios e possibilidades teóricometodológicas de como tratar as memórias/ documentos escritos na pesquisa/ensino de história.

No que toca a atuação do professor de história, segundo Fernando Seffner, alguns elementos como os saberes da disciplina e os saberes da docência precisam ser levados em consideração. Em linhas gerais, os saberes da disciplina compõem-se dos conteúdos de história, os modos de produção do conhecimento histórico, "as teorias da história, os conceitos de tempo, espaço, cultura, nação, acervo, documento, fonte, fato histórico, memória, monumento, educação patrimonial e muitos outros, bem como a historiografia de cada período e os modos de ensino" (SEFFNER, 2011, p. 1). Já os saberes da docência:

São em geral saberes de caráter prático [...] constituem aquilo que um professor aprende ao longo dos anos de exercício docente, saberes muito diversos, em geral pouco sistematizados e pouco refletidos, pouco discutidos, pouco valorizados, mas essenciais 
para a gerência e condução das aulas e para a 'sobrevivência' do professor no ambiente escolar (SEFFNER, 2011, p. 2).

No processo educativo, a educação patrimonial, além de desenvolver a sensibilidade e a consciência dos educandos para a importância da preservação dos bens culturais, tem, ainda, por finalidade a utilização de novos materiais no ensino de história que podem ir além ou somar-se aos livros didáticos, além de propiciar vivências e aprendizagens fora dos espaços escolares. Para tanto, Ivo Matozzi destaca algumas condições metodológicas:

\begin{abstract}
A primeira condição é que as experiências de aprendizagem se desenvolvam com a utilização dos bens culturais originais: monumentos, arquiteturas, fontes de arquivo, peças de museus, sítios arqueológicos, quadros autênticos, etc. A segunda condição é que sejam objeto de observação e de uso para produzir informações. A terceira condição é que esses sejam colocados em relação com o contexto e com a instituição que os tutela [...] (MATTOZZI, 2008, p. 149).
\end{abstract}

No exercício de reflexão da documentação paroquial, aqui selecionada para a construção do texto, utilizarei as propostas do ator em diálogo com três dimensões do documento desenvolvidas por Miriam Hermeto (2012) na abordagem sobre a utilização de canções populares brasileiras no ensino de história: a dimensão material, a dimensão descritiva e dimensão explicativa. Em linhas gerais, a dimensão material visa a estabelecer a relação entre o suporte em que se encontra a documentação e o tipo de documento com o qual se pretende trabalhar. O objetivo central é compreender como a documentação foi produzida para que possa comunicar suas próprias ideias sobre história.

A dimensão descritiva se refere ao tema e ao objeto. Implica identificar a(s) temática(s) a partir dos elementos textuais; os processos históricos a que se referem; e quem são os sujeitos da ação no tempo em que a ação acontece.

Finalmente, a dimensão explicativa, que em linhas gerais, alude à abordagem do tema e às versões teórico-metodológicas e historiográficas sobre o objeto. A análise dessa dimensão visa à percepção de que existem conceitos e métodos de pesquisa relacionados ao tema/objeto e que eles delimitam a forma como se constrói a interpretação. A proposta é possibilitar ao aluno compreender qual é o lugar social de produção do texto/documento; entender qual é a versão 
histórica apresentada para o tema; e criar, enfim, explicação para o tema, utilizando corretamente conceitos históricos.

As condições propostas por Matozzi (2008) e as dimensões do documento sugeridas por Hermeto (2012) precisam dialogar com propostas didáticas que viabilizem o estudo das memórias. Essas dimensões serão intercaladas com sequências de ensino, que para Aguiar Jr. ${ }^{3}$ (2005) citado por Hermeto (2012. p. 149-150) são: "um conjunto organizado e coerente de atividades abrangendo um certo número de aulas, com conteúdos relacionados entre si". A sugestão é que se criem, didaticamente, sequências de ensino, baseadas em um quadro panorâmico que envolve problematização, desenvolvimento da narrativa, aplicação de conhecimentos e reflexão/síntese.

A problematização "tem uma dupla função no processo de ensinoaprendizagem: permitir ao professor identificar os conhecimentos prévios dos alunos acerca do tema que será estudado e sensibilizar os estudantes para o estudo do tema, intelectual e emocionalmente" (HERMETO, 2012, p. 149). As questões que fundamentam a sequência de ensino podem ser assim enunciadas: o que é um arquivo e quais informações os bens culturais originais, a documentação, no caso dos registros paroquiais, poderão produzir e acrescentar para o conhecimento sobre a formação familiar, por exemplo, de uma dada sociedade?

Para o trabalho com educação patrimonial a partir dos registros paroquiais a problematização deverá ser direcionada para algumas atividades.

A Atividade 1, consiste na observação de um arquivo eclesiástico. Antes do contato com o arquivo, o professor deverá orientar os alunos para a realização de leituras que possibilitem desenvolver conhecimentos básicos sobre o que é um arquivo, como os arquivos eclesiásticos foram formados, qual sua distribuição e conservação no Brasil contemporâneo. A leitura de textos pode prestar apoio ao professor e subsidiar aos alunos dessas informações básicas.

Os arquivos, de maneira geral, podem ser entendidos como:

3 AGUIAR Jr, Orlando. O planejamento de ensino - Projeto de Desenvolvimento Profissional de Educadores. Módulo II. Belo Horizonte: Secretaria de Estado de Educação de Minas Gerais, 2005. 
Conjunto de documentos, quaisquer que sejam suas formas ou seu suporte material, cujo crescimento se deu de maneira orgânica, automática no exercício das atividades de uma pessoa física ou jurídica, privada ou pública, e cuja conservação respeita esse crescimento sem jamais desmembrá-lo (FARGE, 2009, p. 12).

No Brasil, segundo Carlos Bacellar (2006), as principais instituições arquivísticas que hoje guardam acervos manuscritos de caráter permanente são arquivos do Poder Executivo, compostos de correspondências como ofícios, requerimento, listas nominativas, matrículas de classificação de escravos, listas de qualificação de votantes, documentos sobre imigração e núcleos colônias, matrícula e frequência de alunos, documentos de polícia, documentos sobre obras públicas, documentos sobre terra; arquivos do Poder Legislativo, como atas e registros; arquivos do Poder Judiciário, representados pelos inventários, testamentos e processos cíveis; arquivos cartoriais, como notas e registro civil; arquivos privados, onde se têm documentos particulares de indivíduos, famílias, grupos de interesses ou empresas; e arquivos eclesiásticos, compostos por registros paroquiais, processos e correspondências.

No que diz respeito à formação dos arquivos paroquiais, em particular, desde a criação do Concílio de Trento, século XVI até o final do século XIX, com o advento da República, da separação entre a Igreja e o Estado, da institucionalização e do lavramento dos registros civis de batismo, matrimônio e óbito, foram funções exclusivas da Igreja. Sob os auspícios das leis eclesiásticas, e como uma das formas de controlar, vigiar a população, definiram-se regras para padronizar os registros dos principais sacramentos que marcavam a passagem dos diversos momentos da vida dos católicos. Assim, os padres foram ensinados a registrar os matrimônios, batismos e mortes.

No entanto, essa normalização levou certo tempo para acontecer e, de acordo com Sérgio Odilon Nadalin (1994, p. 31), "tais normas foram completadas somente no século XVIII, por ocasião da instituição do Rituali Romanum que além de definir como fazer o assentamento, ensinava a realizar contagens periódicas das paróquias". Para o autor, alguns fatores contribuíram para que tais objetivos não fossem plenamente alcançados como, por exemplo, as peculiaridades do povoamento e da colonização, bem como o tamanho da população e a rarefação do território, com seus vazios demográficos. Assim, 
"essas questões poderiam justificar a lacuna entre as ordenações da Igreja Católica e, no que concerne aos registros paroquiais sua definitiva implantação no Brasil Colonial" (p.31). Problemas, esses, "naturalmente conjugados com outras explicações possíveis para a falta de registros anteriores ao século XVIII, entre as quais a simples perda da documentação" (p. 31).

Nesse sentido, Sheila de Castro Faria nos oferece um perfil geral da localização e características dessa documentação, principalmente as referentes ao período colonial, o que vem enfatizar as prováveis dificuldades encontradas, por parte dos historiadores brasileiros que decidem com ela trabalhar, haja vista que:

Espalhadas pelas paróquias interioranas e com evidentes falhas seqüenciais, além das próprias características da sociedade brasileira: grande migração, diversidade de sobrenomes de pessoas de uma mesma família consanguínea e presença de uniões não legalizadas pela Igreja, o que dificulta o acompanhamento da trajetória das famílias individualmente (FARIA, 1997, p. 253).

Para o século XIX "as fontes existem, em inúmeras localidades, em estado de conservação relativamente bom, seriadas e acessíveis ao pesquisador" (FARIA, 1997, p. 253)

A despeito das considerações de Sheila de Castro Faria, em relação à disposição e conservação dos registros paroquiais, nas paróquias interioranas, o Arquivo da Diocese de Limoeiro do Norte (ADLN), no Ceará, lugar de memória onde se encontra a documentação a ser trabalhada, a seguir, não foge à regra. Composto, basicamente de registros de casamentos, batismos e óbitos, com exceção de alguns livros, em estado razoável de conservação, esse arquivo dispõe de um acervo que se inicia em meados do século XVIII, percorrendo os séculos XIX e XX, abrangendo várias paróquias da Região Jaguaribana-CE. ${ }^{4}$

\footnotetext{
${ }^{4}$ Embora o suporte de memória, aqui trabalhado, seja o ADLN, é importante esclarecer que as orientações metodológicas sugeridas podem ser realizadas para qualquer Arquivo Eclesiástico do Brasil, sobretudo, no que diz respeito ao tipo documental. A escolha por trabalhar esse arquivo e parte de seu acervo também não é aleatória. Na verdade, advém da experiência de pesquisa da autora desse trabalho, cuja referência é CHAVES, Elisgardênia de Oliveira. Viver e morrer: uma análise sobre a configuração sócio-familiar na freguesia de Limoeiro - CE, (1870 a 1880). 2009. 184 f. Dissertação (Mestrado em História Social) - Universidade Federal do Ceará, 2009. Esse estudo teve como principal objetivo compreender a configuração sociofamiliar da freguesia de
} 
A par da primeira condição de Ivo Matozzi (2008), acima referida, com especificidade para a documentação escrita e manuscrita que compõem os arquivos paroquiais - os registros de casamentos, batismos e óbitos - sem desconsiderar a importância da utilização dos lugares e suportes da memória, para além dos espaços escolares, como momentos para vivência de aprendizagens de História, hoje, a variedade de arquivos digitais tem facilitado bastante o acesso a documentação.

Nesse sentido, o trabalho dos Mórmons (Igreja de Jesus Cristo dos Santos dos Últimos Dias) que "visando a reconstrução de árvores genealógicas e a conversão retroativa dos antepassados, levou-os a desenvolver intenso trabalho de coleta e pesquisa em todo o mundo" (BACELLAR, 2006, p. 41). O admirável acervo microfilmado, localizado em numerosos centros de atendimento por todo o país, inclusive em cúrias, podem ser conseguido sem grande custo, em muitos casos, gratuitamente. ${ }^{5}$

No entanto, na falta da disposição dos arquivos online ou na opção do próprio professor/pesquisador ir ao arquivo, sozinho ou acompanhado dos alunos, uma metodologia viável é fotografar a documentação e trabalhar o material em outros locais fora dos espaços arquivísticos.

A meu ver, isso facilita o trabalho por muitos motivos. Os arquivos de natureza religiosa nem sempre são de fácil acesso. Os acervos estão reunidos nas cúrias diocesanas, "sob os cuidados de serviços de arquivo em geral bastante precários e desconfortáveis, que costumam improvisar o atendimento quando do surgimento de um pesquisador" (BACELLAR, 2006, p. 39).

Por localizarem-se nas cidades sedes das cúrias diocesanas, o acesso direto, em muitos casos, demanda deslocamentos de cidades vizinhas ou de localidades rurais. Além do que o manuseio da documentação exige um mínimo de formação para que os escritos, via de regra, já tão desgastados pelo tempo, pelas formas de cuidados, não se deteriorem ainda mais.

Limoeiro na década de 1870. O esforço é, então, transformar parte dessa experiência de pesquisa na produção de material para o ensino de história.

5 Disponível em: https://familysearch.org/search/collection/list\#page=1\&region=CENTRAL_SOUTH AMERICA. Acesso em: 05 ago. 2013. 
Muitos arquivos públicos possuem serviços de reprodução de documentos e dispõe de microfilmes, xerox e scanner para disponibilizar os papéis em CDs. Essas duas práticas, além de custar caro, tem sido rejeitadas, pois "alega-se, de maneira geral que as luzes da copiadora teriam efeitos destrutivos sobre as fibras das folhas de papel" (BACELLAR, 2006, p. 60). Dentre outras opções, tem sido comum o recurso da fotografia digital sem o uso de flash. Para o caso do $A D N L$, que não dispõe de nenhum desses recursos, a opção de apresentar o arquivo e documentação fora do arquivo pode ser feita pela fotografia digital.

É interessante que o professor solicite aos alunos que façam uma viagem ao monumento, no caso o ADNL, com paradas em três diferentes momentos: a vista panorâmica do Edifício da Cúria Diocesana de Limoeiro do Norte, o espaço de pesquisa e o acervo documental eclesiástico.

Figura 1- Edifício da cúria Diocesana de Limoeiro do Norte-CE e espaço de pesquisa do Arquivo. (ADNL)

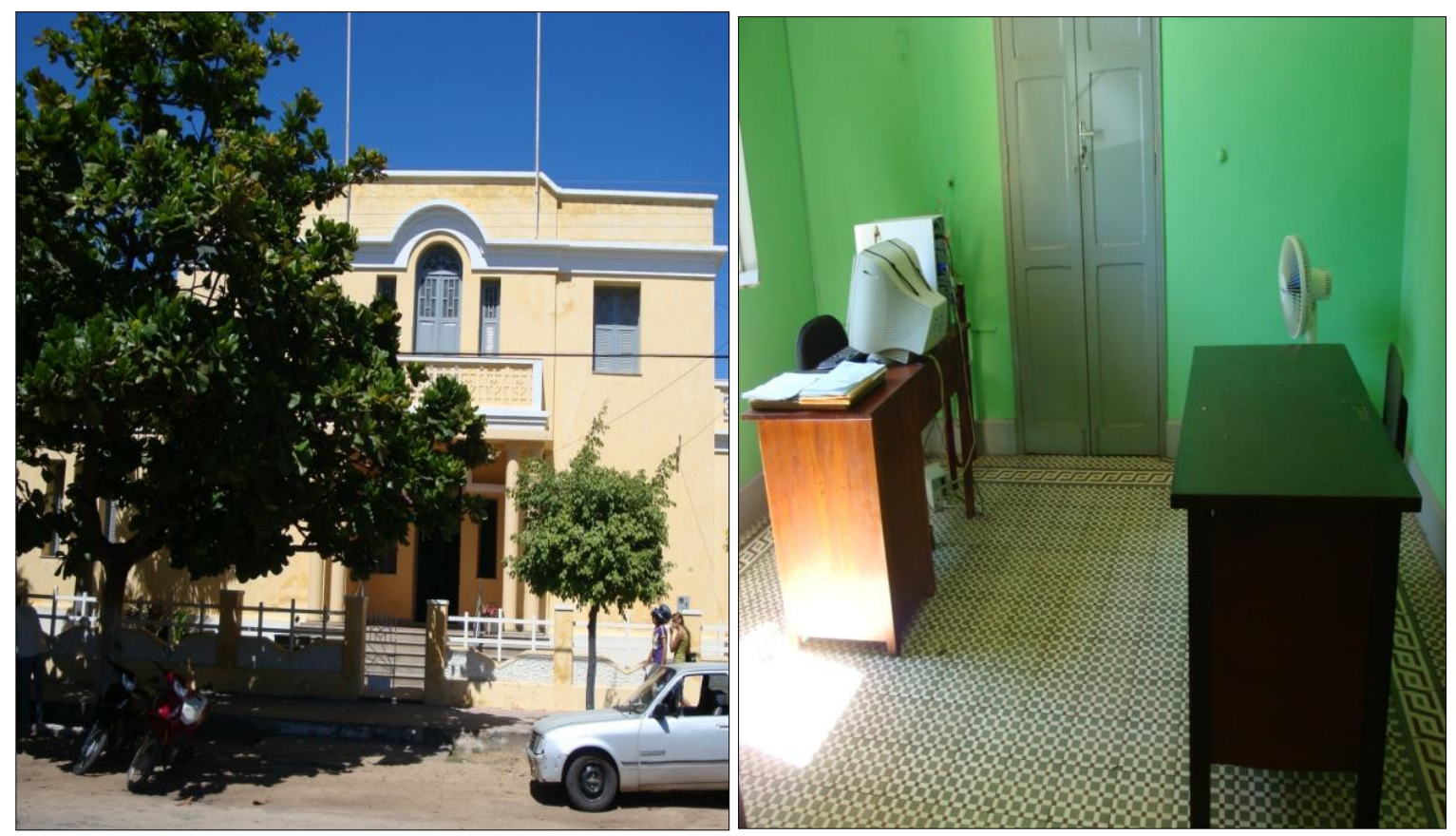

Fonte: Arquivo pessoal da autora.

Figura 2 - Acervo documental eclesiástico do Arquivo da Diocese de Limoeiro do Norte-CE. (ADNL) 

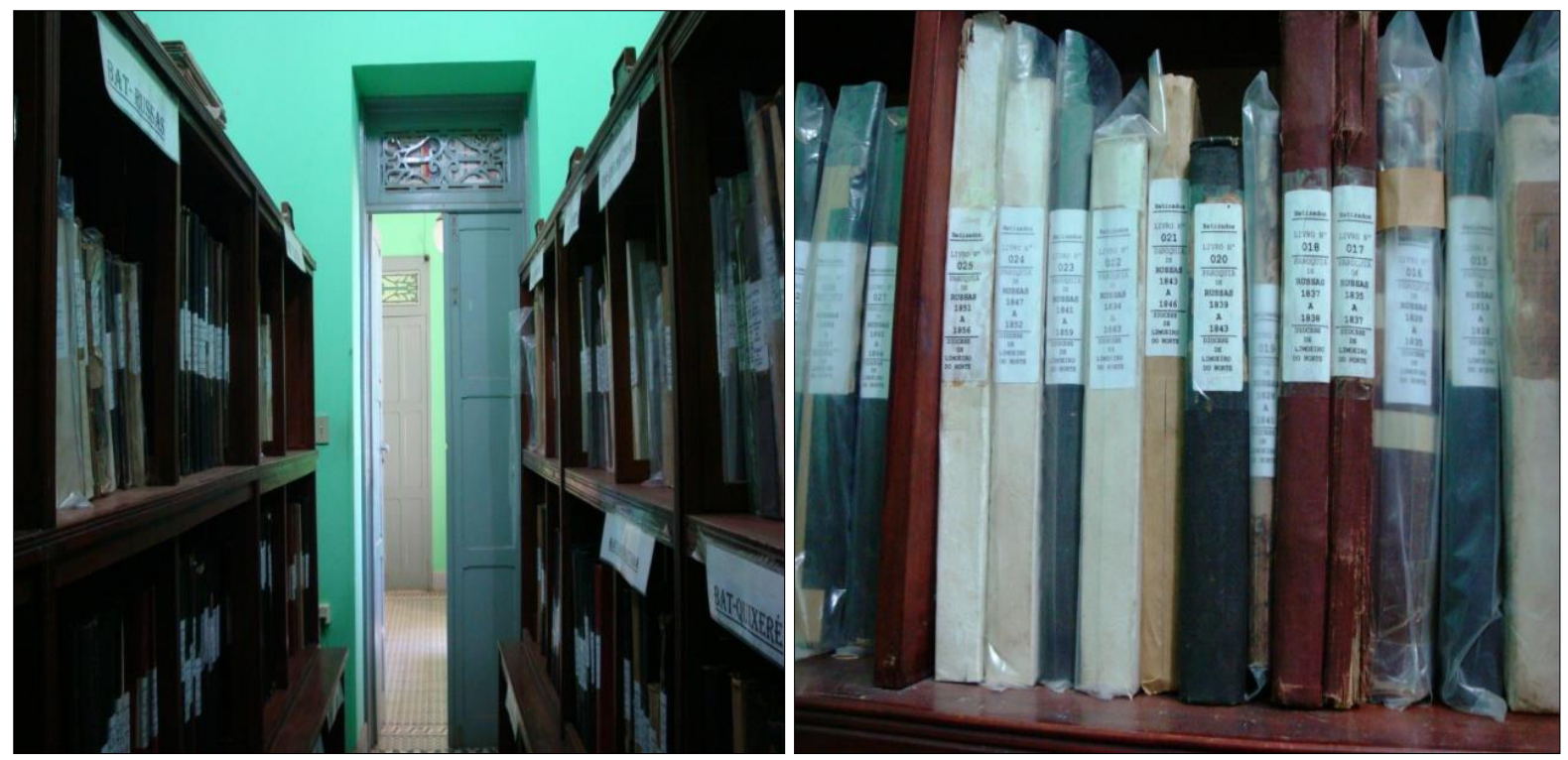

Fonte: Arquivo pessoal da autora.

Na Atividade 2, o professor deve proporcionar a leitura da documentação visando ao reconhecimento da grafia, compreensão de como se estrutura os documentos eclesiásticos, quais informações que esses bens culturais originais poderão produzir e acrescentar para o conhecimento.

É importante esclarecer que o usuário de arquivos escritos precisa ter formação mínima para lidar com esse tipo de documento/fonte. Uma das maiores dificuldades, sobretudo nos primeiros contatos com os manuscritos, é a leitura paleográfica. Contudo, com esforço contínuo é possível alcançar qualidade na leitura.

Além disso, cursos e consultas a dicionários como, por exemplo, o Dicionário de Abreviaturas (FLEXOR, 2008) podem facilitar o desenvolvimento da escrita paleográfica que visa a transcrever fielmente o original ${ }^{6}$ "reproduzindo a grafia, as abreviaturas, enfim, suas características de época" (BACELLAR, 2006, p. 59). Outra opção é modernizar o texto, de acordo com a gramática corrente. Seja como for, é importante que se observe as normas de transcrições.

Inicialmente, depois de apresentar aos alunos a documentação original, instigando-os a leitura da grafia, é viável que o professor tenha exemplares

\footnotetext{
${ }^{6}$ As normas técnicas, transcrição e edição de documentos manuscritos estão disponíveis no site www.aab.org/normtec.htm.
} 
digitados e distribua aos alunos para que se compare e se perceba o nível de dificuldade e a desenvoltura na leitura paleográfica. Esse processo facilita o estudo dos conteúdos a partir das temáticas propostas.

Figura 3 - Livro e folha de batismo originais do acervo eclesiástico do Arquivo da Diocese de Limoeiro do Norte-CE. (ADNL)
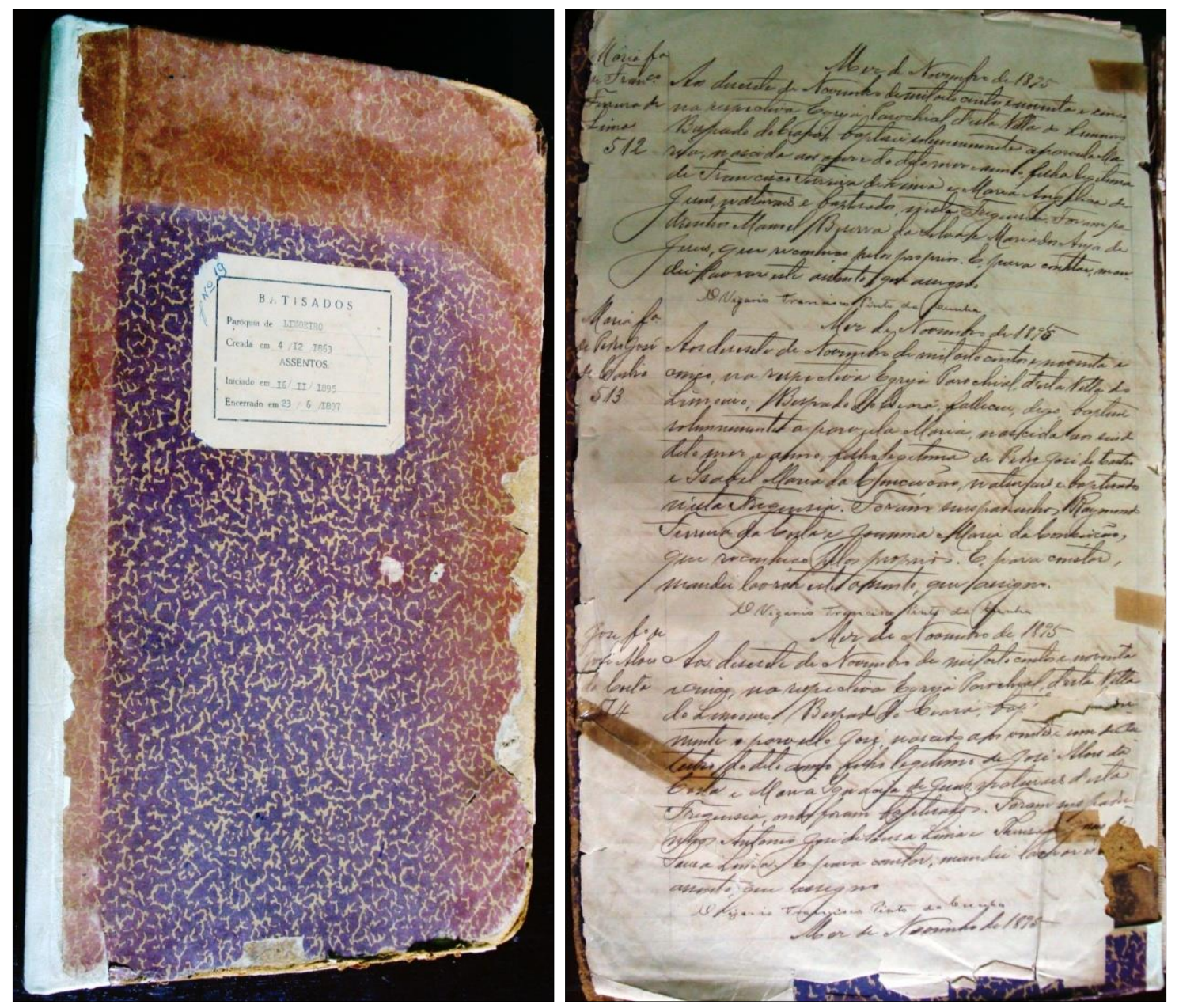

Fonte: Arquivo pessoal da autora.

Os exemplos, a seguir, representam transcrições na íntegra de registros de casamentos, batismos e óbitos. Indicam passagens sacramentadas que permeavam toda a vida dos cristãos: nascimento, casamento e morte. Para essa seleção de documentos, o objetivo é acompanhar a família de Manoel Francisco da Silva e Maria Francisca de Jesus que, no período de cinco anos, casaram e tiveram filhos, dos quais encontramos as certidões de nascimento de um deles e a de óbito de um outro, como também da esposa-mãe. Vejamos: 
Aos vinte dias do mês de Abril de mil oitocentos setenta e cinco, nesta Matriz do Limoeiro o padre Joaquim Rodrigues de Menezes e Silva administrou o sacramento do matrimonio aos contralventes Manoel Francisco da Silva e Maria Francisca de Jesus, e Ihes lancei as bênçãos nupciais depois de confessados e examinados em Doutrina Cristã presentes as testemunhas José de Castro Silva e Maria José Gonçalves Malveira. E para constar mandei fazer este assempto em que me assigno (VIGÁRIO FRANCISCO RIBEIRO BESSA - ADNL - LIVRO DE CASAMENTO No 01, p. 94)

Joaquim, pardo, filho legitimo de Manoel Francisco da Silva e Maria Francisca de Jesus, nasceu aos 26 de Março de 1880 e aos 22 do mesmo mês e ano foi solenemente baptizado nesta Matriz por mim abaixo assignado. Forão seus padrinhos Camillo Brasiliense de Hollanda Cavalcante e Anna Ribeiro de Hollanda Cavalcante. E para constar faço este em que me assigno (VIGÁRIO JOAQUIM RODRIGUES DE MENEZES SILVA - ADNL - LIVRO DE BATISMO No 04, p. 109).

Maria, parda, de edade 3 anos, filha legitima de Manoel Francisco da Silva e Maria Francisca de Jesus, falleceu de beri-beri aos 19 de Julho de1878 e no dia seguinte envolto em branco e encomendada por mim abaixo assignado, foi sepultada no cemitério público desta Villa. E para constar mandei fazer o presente em que me assigno (VIGÁRIO JOAQUIM RODRIGUES DE MENEZES SILVA - ADNL LIVRO DE ÓBITO NO 01, p. 94).

Maria Francisca de Jesus, parda, cazada que foi com Manoel Francisco da Silva, morador na Villa, com edade de 30 anos depois de socorrida com os Sacramentos da Penitência e Extrema-unção, pelo abaixo assignado falleceu de uma suspensão aos 18 de Novembro de 1880 e no dia seguinte, encomendada e amortalhada em branco, digo de preto, foi sepultada no cemitério desta Villa e para constar mandei fazer o presente em que me assigno (VIGÁRIO JOAQUIM RODRIGUES DE MENEZES SILVA - ADNL LIVRO DE ÓBITO No 04, p. 37).

Essa família, bem como a de escravos, a seguir, representam uniões constituídas através do casamento cristão:

Aos 14 e Julho de 1876 nesta Matriz do Limoeiro administrei o sacramento do matrimonio aos contralventes Lucio Lopes e Felicia Maria, escravos de Izeqhiel Lopes de Andrade, e Ihes lancei as bênçãos nupciais depois de confessados e examinados em Doutrina Cristã presentes as testemunhas José Gonçalves Malveira e Antonio Candido Malveira. E para constar mandei fazer este assempto em que me assigno (VIGÁRIO JOAQUIM RODRIGUES DE MENEZES E SILVA - ADNL - LIVRO DE CASAMENTO NO 02, p. 142). 
Para além da formação de famílias pelo viés católico, não podemos esquecer dos arranjos familiares, para os quais os registros de batismos e óbitos trazem muitas evidências, como, por exemplo, o registro de batismo de Pedro, filho natural de Francisca Maria dos Prazeres, e o de Maria, parda, filha natural de Quitéria Maria da Conceição :

Pedro, filho natural de Francisca Maria dos Prazeres, nasceu aos 6 de Junho de 1872 e foi baptizado Solenemente aos 15 do mesmo mês e ano, nesta Matriz pelo Padre Alexandre Correia de Araújo Mello, sendo seus padrinhos: José Panteão dos Santos e Maria Gomes dos Santos. E para constar mandei fazer o presente em que mim assigno (VIGÁRIO FRANCISCO RIBEIRO BESSA - ADNL LIVRO DE BATISMO No 04, p. 170).

Maria, parda, filha natural de Quitéria Maria da Conceição, falleceu de bexigas a vinte e oito de Maio de mil oito cento setenta e quatro, com idade de um ano, foi sepultada no cemitério público desta Villa, depois de encomendada por mim abaixo assignado, em volto em branco, aos vinte e nove do mesmo mês e ano. E para constar mandei fazer este assento em que me assigno (VIGARIO FRANCISCO RIBEIRO BESSA - ADNL - LIVRO DE ÓBITO No 1, p. 11).

As temáticas e os conteúdos a serem trabalhados ficam a critério do professor. Como podemos perceber, as possibilidades são amplas: configuração populacional, formação familiar, condição social: livres e escravos, religiosidade, causas-mortis, mortalidade infantil, entre tantos outros. Para o desenvolvimento dessa proposta didática, selecionamos a temática da família, com ênfase para as características da constituição populacional, as tipologias e formas de organização mais presentes na sociedade em estudo, bem como a desestruturação das famílias pela morte.

A sequência de ensino - desenvolvimento da narrativa - "deve apresentar as elaborações da ciência de referência, devidamente construídas no âmbito do saber escolar" (HERMETO, 2012, p. 149). É, portanto, "o momento em que o aluno toma contato com a abordagem teórica que o professor escolheu para o tema, a partir de discursos científicos da disciplina" (p. 149). As sequências de aulas para essa fase deverão desenvolver-se a partir de duas atividades. 
Na Atividade 3, o professor ministrará uma série de aulas expositivas e dialogadas sobre o tema família no Brasil, devendo amparar-se em uma bibliografia básica:

- discussão historiográfica acerca da temática da família e partindo do pressuposto da organização familiar através dos sacramentos cristãos do casamento. Enfatiza-se, ainda, os entraves burocráticos criados pela Igreja, bem como os sociais, políticos e econômicos, na realização desse ato, enfrentados pela população livre e escrava (cf. BACELLAR, 2001; LORDELLO, 2002; SAMARA, 2003; SILVA, 1978; SLENES, 1999; VIDE, 2007);

- como consequência desses entraves ou por motivos outros que variam entre escolhas, valores morais ou culturais, entre as formas de organização familiar, além da conjugal, estava, para a Igreja Católica, as famílias "transgressoras", formadas por amores ilícitos, uniões concubinas ou consensuais. A partir de atas de batismos e óbitos quando indicam apenas a filiação materna e denominam os filhos de pais não casados ou mães solteiras de naturais, problematiza-se a "legitimidade" na formação das famílias livres e escravas (cf. TORRES-LONDOÑO, 1999; PRAXEDES, 2003);

- com o batismo de um filho, além da incorporação reconhecida do mesmo ao seio familiar, o batizando com seus pais ampliavam os laços familiares, já que ele pressupunha, também, apadrinhamento da criança. Por, simbolicamente, os padrinhos tornarem-se os pais espirituais e responsáveis pela formação moral e religiosa dos afilhados, a escolha dos compadres não se dava de forma aleatória, havendo, portanto, uma rede de preocupações, interesses e confiança em jogo, daí analisa-se o significado das escolhas por parte da população livre e escrava de seus compadres - pais espirituais de seus filhos (cf. ARANTES, 1993; VASCONCELLOS, 1997);

- desse modo, após uma longa discussão a respeito dos modos de viver e de formação das famílias, finalmente com as causas-mortis, analisa-se a interrupção da dinâmica sociofamiliar. Através dos registros de óbitos, abordam-se questões relacionadas às mortes da população responsáveis 
pelo desmonte familiar. Finalmente, os socorros espirituais prestados pelos padres às famílias, haja vista os significados que adquiriam na hora da partida. Na crença cristã, para que a alma fizesse uma boa viagem e pudesse descansar em paz no paraíso celeste, era imprescindível que o moribundo recebesse a Extrema-Unção. Daí analisa-se, também, a simbologia ou sensibilidades envolvidas através desse último sacramento (cf. CHALHOUB, 1996; RODRIGUES, 1997; REIS, 1991; UJVARE, 2003).

$\mathrm{Na}$ Atividade 4, recomenda-se que se solicite aos alunos que se dividam em grupos. Parte dos grupos trabalhará com os registros de casamentos, outra parte com os assentos de batismos e uma terceira parte com as atas de óbitos. O primeiro exercício será de leitura e reflexão sobre o conteúdo do documento. Em seguida, os grupos deverão preencher uma ficha com alguns critérios de análise do documento.

Para as atas de casamentos, deverão ser preenchidos: data da cerimônia, em alguns casos local e horário, padre celebrante, a cor dos noivos, o nome dos cônjuges, naturalidade, filiação, naturalidade e condição civil dos pais, as bênçãos para o sacramento e os nomes das testemunhas.

Para os batismos, deve-se completar: o nome do batizando, data e local do batismo, cor, filiação (se filho legítimo, o nome dos pais, se filho natural, o nome da mãe, se filho legitimo de escravos, o nome dos pais, se filho natural de escrava, o nome da mãe e proprietário a quem essa pertencia), pároco celebrante, padrinhos ou representantes destes.

Finalmente, para os registros os óbitos, é necessário que se preencha: nome, cor, idade, causa da morte, data do falecimento, se se trata de um párvulo (a) (nome utilizado nos livros para se referirem às crianças), o nome de seus pais para os filhos legítimos ou o nome da mãe para os filhos naturais, quando se trata de filho de escrava se livre ou liberto, bem como o nome do proprietário da mãe, condição social (livre ou escravo), estado civil, cônjuge, cor da vestimenta fúnebre, sacramento da extrema-unção recebido ou não, nome do padre responsável pela paróquia e pela realização do ritual fúnebre, e o cemitério onde foi realizado o sepultamento. 
Ao final da atividade, discuta as informações presentes na documentação, a temporalidade, a espacialidade as quais se reportam, identificando as pessoas nelas envolvidas.

Em seguida parte-se para a aplicação dos conhecimentos que "deve apresentar obstáculos cognitivos para os alunos de forma que eles necessitem usar as referências teóricas estudadas nas atividades de desenvolvimento da narrativa" (HERMETO, 2012, p. 149).

Para a Atividade 5, o professor deverá orientar os alunos a desenvolverem uma ação voltada para uma pesquisa sobre os temas históricos:

- equipes responsáveis pelos registros de casamentos: a organização familiar através dos sacramentos cristãos do casamento para livres e escravos;

- equipes a cargo dos assentos de batismos: a "legitimidade" na formação das famílias livres e escravas e as relações de compadrio;

- equipes designadas a trabalharem com as atas de óbitos: as causas-mortis e os significados da extrema-unção para o momento da morte.

Na Atividade 6, grupos deverão ser orientados para a montagem e apresentação de seminários com os dados de pesquisa para socialização dos resultados com a turma.

Por fim, a última sequência de ensino - reflexão sobre o que foi aprendido consiste em "promover uma tomada de consciência e formalizar os conhecimentos construídos." (HERMETO, 2012, p. 149)

A Atividade 7, propõe a produção de um quadro comparativo, do mesmo tipo documental produzido na Atividade 4, na qual os alunos devem realizar uma nova pesquisa em documentos da mesma natureza, porém contemporâneos. Esses documentos podem ser encontrados em diferentes suportes de memórias, como igrejas, cartórios, arquivos particulares da própria família, de amigos e/ou de vizinhos.

Recomenda-se que o professor proponha uma reflexão a partir das questões: como as memórias são produzidas, ontem e hoje; como essa sociedade do presente se organiza em família, procura pelos sacramentos católicos, adoece, morre e realiza seus ritos fúnebres? O objetivo é fazer com que os alunos percebam similitudes e diferenças, mudanças e continuidades. Por 
fim, que se percebam dentro dos processos históricos como sujeitos produtores de memórias, de documentos e de conhecimento, compreendendo que as memórias/documentos produzidas, guardadas e preservadas por seus antepassados e por eles mesmos são o material para a construção da história.

Assim, espera-se conseguir a aproximação de outras três condições metodológicas para o processo educativo voltado para a educação patrimonial:

\begin{abstract}
A quarta condição é que se promova a tomada de consciência de que são a minúscula parte de um conjunto muito mais amplo que permite o conhecimento do passado e do mundo, o prazer de conhecer, a fruição estética. As últimas duas condições requerem que se generalize a descoberta do valor dos bens culturais usados e das instituições e dos sujeitos que os tutelam e os estudam (MATTOZZI, 2008, p.137).
\end{abstract}

A par das discussões travadas ao longo do texto, a Educação Patrimonial voltada para a documentação arquivista, escrita e manuscrita tem muito a contribuir para o aprofundamento das possibilidades, desafios e diálogos sobre a produção do conhecimento/ensino de história.

\title{
Referências
}

ARANTES, A. A. Pais, Padrinhos e Espírito Santo: Um Reestudo do Compadrio. In: ARANTES, A. A. (Org.). Colcha de Retalhos: estudo sobre a família no Brasil. 2. ed. Campinas, SP: Editora da UNICAMP, 1993.

BACELLAR, C. de A. P. Viver e sobreviver em uma vila colonial: Sorocaba, séculos XVIII e XIX. São Paulo: Annablume/Fapesp, 2001.

BACELLAR, C. de A. P. Fontes documentais: uso e mau uso dos arquivos. 2. ed. São Paulo: Contexto, 2006.

BITTENCOURT, C. M. F. Ensino de História: fundamentos e métodos. 2. ed. São Paulo: Cortez, 2008.

BLOCH, M. Apologia da História e o oficio do historiador. Rio de Janeiro: Jorge, 2001.

BRASIL. Ministério da Cultura. Decreto no 3.551 de agosto de 2000. Institui o Registro de Bens Culturais de Natureza Imaterial que constituem patrimônio cultural brasileiro, cria o Programa Nacional do Patrimônio Imaterial e dá outras providências. Brasília, 2000. 
BRASIL. Ministério da Cultura. Lei no. 8.159, de 8 de janeiro de 1991 Lei no 8.159 de 8 de janeiro de 1991 . Dispõe sobre a política nacional de arquivos públicos e privados e dá outras providências.

BRASIL. Ministério da Educação. Lei n 9.394, de 20 de dezembro de 1996. Estabelece as diretrizes e bases da educação nacional. Brasília, 1996

CAIMI, F. E.; CASSOL, F. M. Pesquisando sítios arqueológicos: História e Patrimônio na sala de aula. Entre Ver, Florianópolis, v. 2, n. 1, p. 278-295, jan./jun. 2012.

CHALHOUB, S. Cidade febril: cortiços e epidemias na Corte imperial. São Paulo: Companhia das Letras, 1996.

FARGE, A. O sabor do Arquivo. Tradução de Fátima Murad. São Paulo: Editora da Universidade de São Paulo, 2009.

FARIA, S. de C. História da família e demografia histórica. In CARDOSO, C. F.; VAIFANS, R. (Org.) Domínios da História: ensaio de teoria e metodologia. Rio de Janeiro: Campus, 1997.

FERNANDES, J. R. O. Da identidade nacional à diversidade cultural: novos paradigmas para a preservação do patrimônio histórico. In XXVI Simpósio Nacional de História - ANPUH. Anais... São Paulo: ANPUH, jul. 2011.

FLEXOR, M. H. O. Abreviaturas: manuscritos dos séculos XVI ao XIX. 3. ed. rev. e aum. Rio de Janeiro: Arquivo Nacional, 2008.

HARTOG, F. Tempo e Patrimônio. Varia História, Belo Horizonte, v. 22, n. 36, jul./dez. 2006.

HERMETO, M. Canção popular brasileira e Ensino de História: palavras, sons e tantos sentidos. Belo Horizonte: Autêntica Editora, 2012. (Coleção Práticas Docentes 2).

HERMETO, M.; PEREIRA, M. H. de F. O ensino de história entre trajetórias e epistemologias: o desafio cotidiano de articular teoria e prática na formação do professor de história Saeculum. Revista de História, João Pessoa, v. 27, jul./dez. 2012.

KNAUSS, P. Macaé: usos do passado e sentidos da História Local. In: AMANTINO, M. et al. (Org.). Povoamento, catolicismo e escravidão na antiga Macaé - séculos XVII ao XIX. Rio de Janeiro: Apicuri, 2011.

LE GOFF, J. História e Memória. Campinas: Editora da UNICAMP, 2003.

LORDELLO, J. M. Entre o Reino de Deus e o dos Homens: a secularização do casamento no Brasil do século XIX. Brasília, Editora Universidade de Brasília, 2002. 
MATTOZZI, I. Currículo de História e educação para o patrimônio. Educação em Revista, Belo Horizonte, n. 47, p. 135-155, jun. 2008.

NADALIN, S. O. A demografia numa perspectiva histórica. Belo Horizonte: ABEP, 1994

NORA, P. Entre Memória e História: a problemática dos lugares. Revista Projeto História, São Paulo, n. 10, dez. 1993.

ORIÁ, R. Memória e Ensino de História. In: BITTENCOURT, Circe. (Org.) O saber Histórico na Sala de Aula. São Paulo: Contexto, 1998.

PRAXEDES, V. L. A teia e a trama da fragilidade humana os filhos ilegítimos em Minas Gerais, 1770-1840. 2003. Dissertação (Mestrado em História) - Programa de Pós-graduação, Universidade Federal de Minas Gerais, Belo Horizonte, 2003.

RAMOS, F. R. L. Uma questão de tempo: os usos da memória nas aulas de História. Cad. Cedes, Campinas, v. 30, n. 82, p. 397-411, set.-dez. 2010.

REIS, J. J. A morte é uma festa: ritos fúnebres e revolta popular no Brasil do século XIX. São Paulo: Companhia das Letras, 1991.

RODRIGUES, C. Lugares dos mortos na cidade dos vivos: tradições e transformações fúnebres no Rio de Janeiro. Rio de Janeiro: Secretaria Municipal de Cultura. Departamento Geral de Documentação e Informação Cultural. Divisão de Editoração, 1997.

SAMARA, E. de M. Família, mulheres e povoamento. Bauru - SP: EDUSC, 2003.

SILVA. M. B. N. da. Sistema de Casamento no Brasil Colonial. São Paulo: Fundação Carlos Chagas, 1978.

SEFFNER, F. Saberes da docência, saberes da disciplina e muitos imprevistos: atravessamentos no território do ensino de história. XXVI Simpósio Nacional de História - ANPUH. Anais... São Paulo: ANPUH, jul. 2011.

SLENES, R. W. Na senzala uma flor: as esperanças e recordações na formação da Família Escrava, Brasil Sudeste, Século XIX. Rio de Janeiro: Nova Fronteira, 1999.

TORRES-LONDOÑO, F. A outra família: concubinato, igreja e escândalo na colônia. São Paulo: Edições Loiola, 1999.

UJVARE, S. C. A História e suas epidemias: a convivência do homem com os microorganismos. Rio de Janeiro: Editora SENAC, 2003.

VASCONCELLOS, M. C. de. Que Deus os Abençoe: batismos de escravos em Angra dos Reis (RJ), no século XIX. Revista História \& Perspectivas, Uberlândia. n. 16-17, 1997. 
VIDE, S. M. da. Constituições Primeiras do Arcebispado da Bahia. Brasília: Edições do Senado Federal, 2007.

ZAMBONI, E. Panorama das pesquisas no ensino de História. Saeculum - Revista de História, João Pessoa, n. 6-7, jan./dez. 2000/2001.

Recebido em 28 de agosto de 2013

Aprovado em 13 de dezembro de 2013. 